\title{
Supporting language learning in the three-dimensional model of the ancient Library of Alexandria
}

\author{
István Károly Boda ${ }^{a}$, Erzsébet Tóth ${ }^{b}$, István Csont $^{b}$, \\ László T. Nagy ${ }^{b}$ \\ ${ }^{a}$ Debrecen Reformed Theological University \\ boda.istvan@drhe.hu \\ ${ }^{b}$ University of Debrecen, Faculty of Informatics \\ erzsebet.toth@inf.unideb.hu \\ ist.csont@gmail.com \\ t.nagy.laszlo@hunep.hu
}

\begin{abstract}
Our basic aim of the research is the implementation and gradual improvement of a three-dimensional virtual library model. In the development stage of the first version of the model we chose some illustrious authors who represented the ancient Greek poetry and drama from the 3rd century BC. Their short biography and certain parts of their works formed the selected content of the virtual library model. We designed a four-level hierarchical and scale-free structure based on the original classification scheme of the ancient Library of Alexandria elaborated by Callimachus. We are enhancing the content of the database with additional items of different verbal and/or multimedia text types (e.g. illustrative images, commentaries, concordance and collocation tables, dictionary entries, translations, adaptations, summaries and so on). This additional background information is necessary for us to interpret and understand the old Greek poetical texts better, especially in the case of mythological allusions. Currently we investigate how the collected items can be effectively used in language learning to develop the learners' linguistic competence, and, in general, how the spatial hypertext concept could promote the multidisciplinary use of the model in education. The virtual library model is currently based on PHP/MySQL technology which fully supports the three-dimensional representation capabilities of the VirCA (Virtual Collaboration Arena) system.
\end{abstract}

Keywords: 3D virtual library model, VirCA system, spatial hypertext, 3D 
representation of the library content, text-based language learning

MSC: 68U05; 68U35; 68P20; 68T05; 91E10; 91E40

\section{Why is the Library of Alexandria so important from a cultural aspect?}

The Library of Alexandria is considered to have been the most famous collection of classical (Greek-Roman) antiquity. We can state that it has been embodied a library ideal since centuries demonstrating a symbolic force for public libraries in our days. In addition to this, all the Greek written documents gathered in this library were regarded as eternal values for human culture and erudition. We have to take into consideration the fact that Greek mythology serves as a kind of 'common language' and symbolic basis for the better interpretation and understanding of the old Greek poetical works. The Musaeum or Mouseion ("Institution of the Muses") at Alexandria was a research establishment founded by Ptolemy I Soter and by his son, Ptolemy II Philadelphus at the turn of 4th and 3rd centuries BC. A subsidiary "daughter library" was established by Ptolemy III (Euergetes) in the Temple of Serapis about 235 BC. We can conclude that the creation of the Library of Alexandria and its attendant institutions were significant contributions to developing Alexandria into an intellectual and cultural center in the empire of Alexander the Great. The museum and library operated for many centuries but were destroyed in the civil war that took place under the Roman emperor Aurelian in $272 \mathrm{AD}$.

The Ptolemies considered the Library of Alexandria as a kind of repository for the accumulated erudition of the humanity and as one in which all the written Greek papyrus rolls could be accessed. They made a great decision to follow Alexander the Great's plans to create a universal library; they intended to collect every document. Arising from these the mission and the main goal of the Great Library was to achieve completeness in written Greek literary works. Soon its collection had a size of several thousands of papyrus rolls. During its most flourishing period it is supposed to have contained 490 000, or, according to another authority, involving all duplicates, as many as 700000 volumes $[1,2]$

\section{Hierarchical system of the ancient Greek texts}

Callimachus, a scholar of encyclopedic knowledge and erudition was the third director of the library between 260 and $240 \mathrm{BC}$. His famous library catalogue had a name Pinakes coming from the suitable parts of the catalogue on papyrus leaves which were stuck (probably written) on wooden tablets. Those tablets were put above library cases (or shelves) to enhance a search for papyrus rolls and to make their reshelf more efficient. The full title of the catalogue was as follows: Tables of Those Who Have Distinguished Themselves in Every Form of Culture and of 
What They Wrote. It was one of the first recorded registers that identified, and categorized a library's holdings. Focusing on the author, Callimachus attached a short biography to each author's name and he characterized the originality of each document. In several cases the title was seldom unambiguous, therefore he always added the first line of the work to his catalogue and recorded how many lines the given work contained [1].

The catalogue comprised 120 books (rolls), and it listed approximately 200000 papyrus rolls. Since the library of the Mouseion included nearly all of the ancient Greek works, the catalogue is thought to be a national bibliography of contemporary Greek literature too. It can be also considered as ancestor of bibliography and science history because of its biographical notes [3]. Although now it was lost, it was used in the Byzantine period as a standard reference work of Greek literature.

The structure of Callimachus' catalogue reflecting the contemporary scientists' and literary men's intellectual system had two different levels:

- At the higher level there was a categorization of the ancient Greek authors by genre that gave the basic concept of the division.

- At the other level each group was put into alphabetic order by author's name.

Callimachus arranged the library documents into two main parts: poets and prosaists. In both categories he devised six sub-groups separately:

- poets: epic poets, elegists, satirical poets, lyrical poets, tragedians, comic playwrights;

- prosaists: historians, speakers, philosophers, physicians, natural scientists, miscellanies (here cookery books were included with a „dining writers" subtitle) $[4,5]$.

\section{The integration of the content into our $3 \mathrm{D}$ virtual library model}

First of all our objective was to implement Callimachus' classification system in our virtual library model. Three illustrious Greek ancient authors were selected who would represent each sub-group within the ,poets" main category. We imitated the same author's approach as Callimachus employed in his catalogue by connecting the author's image or her/his bust with the author' name, and attached a short curriculum vitae to her/him. Using this approach we simply followed the same content layout once available in the Pinakes.

The various content has been integrated into this library model in the following phases:

1. We conducted searches for images closely connected to the authors' life and poetical works. These images provided a wide range of artistic works: graphics, marble reliefs, statues, paintings and maps. 
2. Then we collected and edited a short biography of the chosen old Greek authors. Referring to their important role in Greek literature, we gave a short overview about their life and enumerated the most well-known works they created. Entries in Encyclopedia Britannica and in Wikipedia online sources ${ }^{1}$ were used and checked for this task

3. Taking into account the copyright restrictions, we found suitable English translations of Greek masterpieces. The electronic version of poetical works could be used for this task and they were available in different digitization projects e.g. Perseus Digital Library Project (Tufts University) ${ }^{2}$, Project Gutenberg, Google Books Library Project, California Digital Library (University of California). Among them we call the readers' attention to Perseus Digital Library Project which has built a retrievable database from the old Greek texts both in native language and in English. 3D data models have also been developed with an objective to incorporate them into Perseus Digital Library. In this research project standardized schemas are applied for describing ancient Greek texts [6]. Then these English translations were edited in one page $(\mathrm{A} / 4)$ length and in the appropriate format.

4. Our next challenge was to load all of the collected library content into the VIRCA system in a strict logical order and means according to the special characteristics of the software.

\section{Implementation of the virtual library in a $3 \mathrm{D}$ en- vironment}

In the implementation of our three-dimensional virtual library model (3DVLM) more than three years ago $[7,8]$ we decided to use the excellent $3 \mathrm{D}$ presentation and navigation features of the Virtual Collaboration Arena (VirCA) system developed in the 3D Internet-based Control and Communications Research Laboratory at the Institute for Computer Science and Control (MTA SZTAKI) [9, 10]. In the further development of the library model, the 3D environment of the VirCA system remained the base of the implementation, although we added new presentation features to the model (e.g. different images in the left and right image corridors which serve dual function, browser windows provided by the new version of the VirCA system etc.) $[11,12]$ and we have been developing alternative webbased presentation interfaces as well [12]. In addition, there is a brand new and efficient tool of cyber learning with excellent 3D presentation capabilities called the MaxWhere Seminar system developed by the professionals of the VirCA system. The MaxWhere system uses the $3 \mathrm{D}$ virtual space as a general context and allows us to present online interactive content as well as vivid and intricate details

\footnotetext{
${ }^{1}$ http : //www.britannica.com/EBchecked/topic/14417/Library - of - Alexandria(et passim); http : //en.wikipedia.org/wiki/Library $f_{A}$ lexandria(etpassim $)(2017-04-23)$

${ }^{2}$ http : //www.perseus.tufts.edu/hopper/(etpassim $)(2017-04-23)$
} 
of the presented material. This new 3D presentation tool might also be effectively used for supporting our virtual library model in the future.

A brief summary of the basic concepts of the 3DVLM is as follows. The central part of the 3D model is a virtual room where the selected library content is presented in carefully arranged boxes called cabinets. Each cabinet contains a (verbal or multimedia) text, an image or a browser window inside, and they are curtained or 'veiled' by an appropriate curtain image identifying the content of the cabinet (e.g. by the author and title of the presented text, the portrait of the author etc.). Each cabinet has a label which identifies a corresponding category (e.g. epic poets, elegists, lyrical poets etc.) selected from the ancient classification system of Callimachus. We attached on both sides a maximum of four relevant images to each cabinet in order to help the users find the cabinet they are looking for more easily (if possible, "at first glance" in the 3D environment), or understand and memorize the represented content more clearly and effectively. We called the sequence of images image corridors because they might as well fulfil a kind of 'navigator' function in the 3D environment directing the users to those cabinets which they consider to be important or interesting (see Fig. 1).

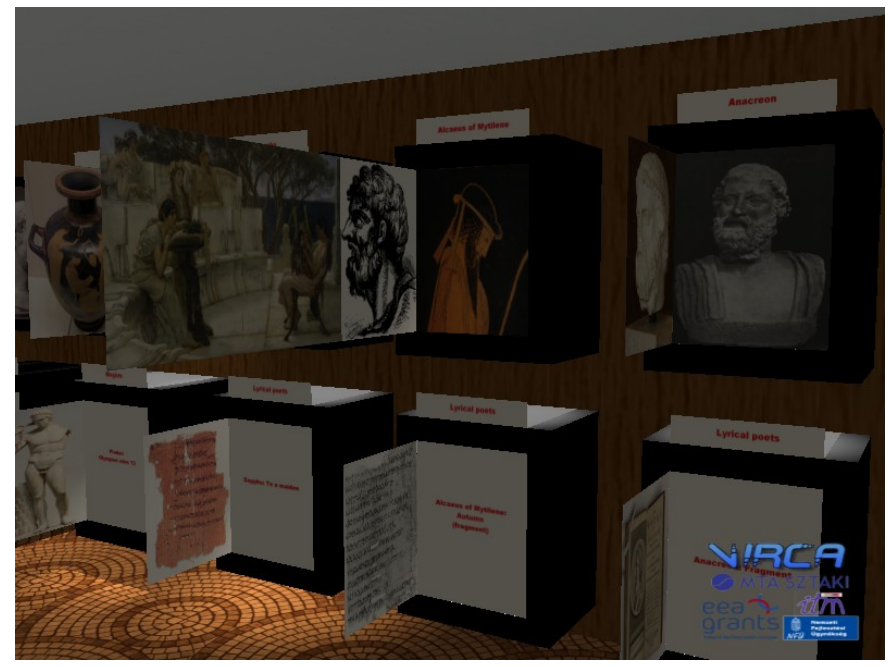

Figure 1: Cabinets on the front wall of the virtual room with image corridors on their left side

The images displayed in the image corridors achieve two different purposes. The images in the left image corridor and the content of the cabinet belong to form a coherent whole (i.e. a 'small world') where the function of the images is to illustrate, explain or complete the content of the cabinet. The images can be ancient maps, paintings, antic sculptures, reliefs, papyruses, book covers, illustrative graphics etc. on the one hand, and selected quotations, explanations, commentaries, plot 
diagrams or maps, brief summaries or reviews of stories etc. on the other hand. The images in the right image corridor may (and usually does) belong to more than one cabinets (or, to be more exact, to the content of the cabinets represented as searchable library items). The basic function of the images is to connect the related library items in order that the users can see or recognize the possible relationships of a selected item and, in turn, memorize its content more easily (with as many associations as possible). The images can present the main source of the content (e.g. as a form of a montage, composite or collage of the corresponding web or book pages or covers), lists of selected sources or references, bibliographies, dictionary or encyclopedia entries etc. on the one hand, and a specific group of concordances, collocation tables, portfolio diagrams, mind maps, semantic graphs or hypergraphs etc. on the other hand. Note that, in addition to the image corridors, the careful arrangement or juxtaposition of the cabinets themselves are also of vital importance with regard to the accessibility to the relevant library content in the two- or threedimensional space $[13,14]$.

In order to take full advantage of the 3D environment we need a dynamic serverbased system which can manipulate the database of the virtual library content, offers an interactive interface for the users to compile and send a search query, and generates multiple views of the search results respectively — using the features of both 2D (i.e. web pages) and 3D (i.e. the VirCA system). The visual grouping of the displayed library content depends on the display interface selected. Using $2 \mathrm{D}$ environment, the main emphasis is on the selected cabinet and the items displayed in the image corridors of the selected cabinet on both sides (note that most items on the right image corridors refer to a certain group of cabinets expressing a given relationship among their content). On the contrary, using $3 \mathrm{D}$ (i.e. the VirCA) environment, the spatial arrangement of the searched cabinets in the virtual room expresses a certain global relationship among them depending on the search query that resulted in the given arrangement.

\section{An example of the possible application of the vir- tual library mdel}

Now that we have introduced the main concepts and basic functions of the 3DVLM let us turn our attention to its possible applications. We will focus now on verbal texts, in our case a poem by Sappho, to demonstrate the possibilities of the 3DVLM. During the reading process, we need a certain amount of dictionary and background knowledge to understand and interpret the text we are just reading. To support this, the selected material should be carefully preprocessed to provide the necessary (or presumed) dictionary and background knowledge for the reader in order that the text could be read (and understood) at once and without much effort [15].

We present an English translation of the poem 'To a maiden' by Sappho which is part of the knowledge base of ancient texts. We attached explanatory texts to two selected points of the poem (in italic letters below) which serve as both dictionary 
entries and commentaries.

Sappho: To a maiden. (Translated by J. Addington Symonds, 1885)[16]

Peer of gods he seemeth to me, the blissful

Man who sits and gazes at thee before him,

Close beside thee sits, and in silence hears thee

Silverly speaking,

Laughing love's low laughter. Oh this, this only

Stirs the troubled heart in my breast to tremble!

For should I but see thee a little moment,

Straight is my voice hushed;

Yea, my tongue is broken, and through and through me

'Neath the flesh impalpable fire runs tingling;

Nothing see mine eyes, and a noise of roaring

Waves in my ear sounds;

Sweat runs down in rivers, a tremor seizes

All my limbs, and paler than grass in autumn, Caught by pains of menacing death, I falter, Lost in the love-trance.

\section{explanation and commentary for line $\mathbf{1}$ and $\mathbf{2}$}

Peer of gods he seemeth to me, the blissful / Man ... = A passionate and jealous woman (probably Sappho herself) is envious of the man who is sitting close beside a striking girl, the object of passionate love. That man looks to the woman so extremely happy, so joyful, that he seems to be equal to the gods as though he is one of them.

\section{explanation and commentary for line $\mathbf{4}$ and $\mathbf{5}$}

... Silverly speaking, / Laughing love's low laughter $=$ The striking girl behaves like she would be one of the ancient goddesses of love (Aphrodite, Circe, or perhaps one of the Sirens known from Odyssey). She is flirting with the man who is sitting close behind her. Her soft speaking and laughter, her low and silvery tone serves to tempt and enchant the man in order to either seduce him or keep him in the eternal state of listening to the stunning voices in silence.

Of course, the main function of the above texts is to explain those parts of the presented English text the meaning of which might be a bit unclear or ambiguous. Although they provide mainly linguistic (or dictionary) knowledge it is worth noticing the emergence of some references to Greek mythology. In this sense, the explanatory texts also include some important elements of the necessary background knowledge, and therefore they provide not only explanatory but 
commentary function as well.

The cabinet containing Sappho's poem can be searched for and selected using either the $2 \mathrm{D}$ or the 3D display interfaces of the 3DVLM. Then the explanations and commentaries presented above can be found as inherent parts of the left image corridor of the selected cabinet. They will surely support the process of reading and understanding the poem, and the success (and the explored beauty) should give enough motivation for the reader to repeat the process more than once. Actually, it is the essence of our 'memorize at once' strategy of learning which involves the development of both the linguistic competence and the background knowledge of the reader. And although this is a very simple (and obviously limited) demonstration of the possibilities of our model, we firmly think that it clearly shows how the gradual development of the knowledge base and the inclusion of carefully preprocessed materials might and would contribute to the achievement of our mission in the future.

\section{References}

[1] Phillips, H., The Great Library of Alexandria?, Library Philosophy and Practice University of Nebraska-Lincoln, (2010) August,

[2] Grüll, T., Könyvtárak és könyvkiadás az ókorban, [Libraries and Publishing of Books in the Antiquity,] in Bevezetés az ókortudományba 1, [Introduction to the Study of Antiquity 1,] Debrecen: Kossuth Egyetemi K., (1996), 223-231.

[3] MacLeod, R., The Library of Alexandria: Center of Learning in the Ancient World, New York: I. B. Tauris and Co. Ltd., (2005)

[4] El-Abbadi, M., The Life and Fate of the Ancient Library of Alexandria, 2nd illustrated ed., Unesco/UNDP (1990)

[5] Wiegand, W., Davis, D. G., Encyclopedia of Library History, New York: Routledge, (1994)

[6] Horn-yeu, S., Jacob, R.J.K., Crane, G. R., The 3D Vase Museum: a New Approach to Context in a Digital Library, in JCDL '04. Proc. of the 4th ACM/IEEECS joint conference on Digital libraries, New York, NY, USA : ACM Press (2004), $125-134$.

[7] Boda, I., Bényei, M., Tóth, E., New dimensions of an ancient Library: the Library of Alexandria, CogInfoCom 2013. Proc. of the 4th IEEE International Conference on Cognitive Infocommunications, (Budapest, Hungary December 2-5), (2013), $537-542$.

[8] Boda, I., Bényei, M., Tóth, E., Csont, I., A three-dimensional virtual library model of the ancient Library of Alexandria, ICAI 2014. Proc. of the 9th International Conference on Applied Informatics, (Eger, Hungary January 29-February 1), Vol. 1 (2014), 103-111.

[9] VirCA: 3D Virtual Collaboration Arena, http://virca.hu/ (2017-05-31).

[10] Galambos, P., Baranyi, P., VirCA as Virtual Intelligent Space for RTMiddleware, AIM 2011. Proceedings of the 2011 IEEE/ASME International Conference on Advanced Intelligent Mechatronics(Budapest, Hungary, July 3-7) (2011), $140-145$. 
[11] Boda, I., Bényei, M., Tóth, E., Csont, I., A 3D virtual library model: representing verbal and multimedia content in three dimensional space, Qualitative and Quantitative Methods in Libraries, Vol. 4., issue 4. (2015), 891-901.

[12] Boda,I., Tóth,E., Csont I., T. Nagy, L., Toward a knowledge base of literary content focusing on the ancient Library of Alexandria in the three dimensional space,, CogInfoCom 2015. Proc. of the 6th IEEE International Conference on Cognitive Infocommunications, (Győr, Hungary October 19-21), (2015), 251-258.

[13] Bernstein, M., Collage, Composites, Construction, Hypertext '03. Proceedings of the 14th ACM Conference on Hypertext and Hypermedia,(Nottingham UK Aug. 2630) (2003), 122-123.

[14] Matias, J. N., Williams P., Comparing Spatial Hypertext Collections, Hypertext '09. Proceedings of the 20th ACM conference on Hypertext and Hypermedia, (Torino, Italy June 29-July 1), (2009), 45-50.

[15] Boda, I., Tóth, E., Csont I., T. Nagy, L., Developing a knowledge base of ancient literary texts in virtual space, CogInfoCom 2016. Proc. of the 7th IEEE International Conference on Cognitive Infocommunications, (Wrocław, Poland October 16-18), (2016), 263-270.

[16] Sappho, To a Maiden, Translated by John Addington Symonds. The John Addington Symonds Pages, http://rictornorton.co.uk/symonds/translat.htm\#maiden (2017-0531) 